\title{
ESTÁNDARES JURÍDICOS INTERNACIONALES: NECESIDAD DE UN ANÁLISIS CONCEPTUAL *
}

\section{MARCELA MOLINA VERGARA**}

RESUMEN: La acepción estándar internacional es parte de la nomenclatura y formación dinámica del derecho internacional. Este, a través de sus diversos instrumentos, ha generado herramientas que permiten a los Estados orientar su actuar y/o construir su normativa interna, siendo muchas veces la base para la formación de completos sistemas jurídicos internos, pero ¿tenemos claridad sobre qué es un estándar? o ¿cuándo algo se convierte en un estándar internacional? ¿Es relevante para el derecho indagar en el significado de estos conceptos? ¿Cómo y hasta qué punto puede esta diversidad lingüística afectar los objetivos del derecho internacional? Sin pretender resolver todas las interrogantes, se ofrece en este artículo un punto de partida de reflexión y discusión sobre este tema, exponiendo algunos de los ámbitos de su aplicación en el derecho internacional. Adicionalmente se discutirá sobre análisis conceptuales similares realizados por la doctrina, estudios donde gramática y derecho se unen con el objetivo de invitar al lector a tomar conciencia y reflexionar sobre los diferentes usos del concepto estándar internacional en el ámbito del derecho, y las implicancias que su aplicación puede traer, en el efectivo resguardo de los derechos que estos estándares se pretenden resguardar.

PALABRAS CLAVE: Derecho internacional; Estándar internacional; Estándares de derechos humanos; Derecho internacional de los derechos humanos.

Fecha de recepción: 3 de marzo de 2016.

Fecha de aceptación: 22 de agosto de 2016.

Abogada, Magíster en Criminología Crítica, Prevención y Seguridad Social de la Universidad de Padua, Italia. Candidata a Doctora en Derecho por la Universidad de Talca. Docente de Responsabilidad Penal Adolescente en la misma casa de estudios. Abogada analista especializada en el Instituto Nacional de Derechos Humanos de Chile (INDH). Colaboradora del centro de estudios sobre los derechos de la infancia y la adolescencia de la Universidad de Talca y colaboradora del Instituto Latinoamericano de Prácticas Restaurativas. 


\title{
INTERNATIONAL LEGAL STANDARD: THE NEED OF A CONCEPTUAL ANALYSIS
}

\begin{abstract}
The concept of "international standard" is widely used in the field of international law. Throughout the years and by means of its wide array of tools, it has provided the States with the necessary implements in order to guide their actions and/or build their internal legislations, becoming frequently the basis for the development of specific laws and statutes. Given the broad scope of application of this concept, and the wide variety of notions linked to it, we believe it is essential to reexamine the use of those terms, not only to clarify its meaning, but also in order to determine to which extent the growth of its legislative scope may interfere with the implementation and successful achievement of the objectives established by any international or regional organization. It should be noted that this issue is of particular relevance today, considering the rising influence of international standards as promoters of national policy reforms, and the creation of new special legal systems. Finally, we must state that it is not within our intentions reaching to an answer to all of the questions arising from this discussion, but to make the reader aware of the different uses of this notion and invite him to reflect on the implications and/or possible contradictions it could pose to the effective protection of the rights the States themselves are intended to guarantee.
\end{abstract}

KEY WORDS: International law; International standard; Human rights standards; Human rights international law

Sumario: 1) Introducción. 2) Intentos de conceptualización. 3) Algunas referencias a estándar internacional. 4) Conclusiones.

\section{1) INTRODUCCIÓN}

Con un poco de observación al mundo jurídico-político y su desarrollo, podemos notar que durante las últimas décadas se ha experimentado una fuerte tendencia a la generación de reformas legales. Latinoaméri$\mathrm{ca}^{1}$ no ha sido la excepción en esta creación normativa, buscando cambiar antiguos paradigmas y/o la creación de nuevos sistemas de justicia ${ }^{2}$ como

\footnotetext{
1 Sousa, Mariana (2007) "Breve panorama de la reforma judicial en América Latina: objetivos, desafíos y resultados”. En El estado de las Reformas del Estado En América Latina. Washington: Publicación conjunta del Banco Mundial y Editorial Mayol, p. 100.

2 PÁsAra, Luis (2010) "Reformas del sistema de justicia en América Latina, cuenta y balance". En Sociología del derecho. Culturas y Sistemas Juridicos Comparados, Vol. I. México: UNAM.
} 
sucedió con la responsabilidad penal adolescente ${ }^{3}$. Estas iniciativas, tienen como principal punto de partida al derecho internacional como fuente inspiradora (u obligatoria) de su desarrollo, teniendo como objetivo adecuar el actuar de un Estado a las exigencias internacionales, o para nuestro interés particular, en sus relaciones con la administración y ejecución de la justicia.

No cabe duda que esta tendencia da por evidente la necesaria inspiración/obligación posada en el derecho internacional por parte de los legisladores nacionales, mirando tanto a sus contenidos y principios, como a sus mecanismos de acción, los cuales están presentes en los diversos y múltiples instrumentos internacionales existentes para cada ámbito del derecho, siendo uno de sus principales mecanismos, la creación de estándares jurídicos internacionales.

Sabiendo que debemos partir desde el derecho internacional, para Kelsen ${ }^{4}$, este es un cuerpo de reglas con las cuales se regula la conducta de los Estados en sus relaciones entre sí, entendiendo estas reglas como ley ${ }^{5}$. Es en este concepto de ley donde podríamos encontrar pistas para entender el alcance de una norma o regla internacional y su diferenciación con una norma interna. En este sentido, analizar sus componentes dogmáticos, sociológicos y filosóficos ${ }^{6}$ nos entrega una aproximación a la comprensión de la necesidad de diferenciación entre los tipos de normas, y cómo estas serán conceptualizadas por el destinatario y/o intérprete de la misma. Este concepto de derecho internacional y sobre todos sus elementos, orientados hacia la utilización de reglas o normas comunes, nos van dando pistas de la actual percepción de estándar jurídico y la amplitud de su utilización.

Con natural seguridad, la frase estándares internacionales es parte referencial de casi la totalidad de las áreas del derecho, la cual, toma aún más fuerza ante la constante migración de las naciones a unirse mediante

3 Beloff, Mary (1998) "Los sistemas de responsabilidad penal juvenil en América Latina". En Infancia, Ley y Democracia en América Latina. Análisis crítico del panorama legislativo en el marco de la Convención Internacional sobre los Derechos del Niño. Bogotá: Editorial Temis/ Depalma, p. 5 y ss.

4 Kelsen (1952) En su obra Los principios del derecho internacional ya anunciaba un derecho de las naciones, capaz de regular todas las materias, incluso aquellas de orden interno exclusivo. Vaticinio que vemos hoy en día cumplido, pero con fines y resultados distintos a los que podría haberse planteado, p. 3.

5 En el mismo texto anterior, se desprende la importancia del concepto de Ley, para entender el alcance y sentido que una norma imperativa internacional puede tener y cómo se diferencia de una ley doméstica o nacional. KeLsen (1952) 4.

6 Toda norma jurídica debe ser analizada desde esta triple perspectiva: cuál es su contenido como norma jurídica positivizada (dogmática jurídica); si cumple los objetivos por los cuales fue creada, es decir su eficacia (análisis sociológico); y el análisis de su legitimidad, es decir la percepción de justicia en su contenido (filosófico-valórica). 
organismos internacionales ${ }^{7}$, la proclamación de las naciones sobre los derechos humanos durante el periodo próximo a la postguerra y la progresiva búsqueda de unificación entre las naciones a consecuencia de la proximidad creada con otros Estados en virtud de la tecnología que nos ocupa hoy en día. Tanto los derechos humanos (DDHH) como el derecho internacional parecen ser vistos como una efectiva herramienta para la protección del ser humano, viniendo así a complementar la labor de los Estados en este sentido ${ }^{8}$. Para algunos, el uso del concepto de DDHH podría no cumplir con los fines para los cuales fue creado debido al empleo extensivo y difuso que los llevarían a perder su fuerza y legitimidad ${ }^{9}$. Mientras más se expanda la lista de lo que se considere como un derecho humano, más se disipa su fuerza, perdiendo la exclusividad que tenía esta clase de derechos por sobre otros ${ }^{10}$, llegando inclusive a clasificaciones que eliminan su carácter de fundamental ${ }^{11}$. Algo similar podría estar ocurriendo con el concepto de estándares jurídicos internacionales, donde su fuerza ha sido disipada o simplemente no conocida debido a la amplitud de su uso y la imprecisión de su contenido.

Haciendo la revisión de expresiones de uso corriente como esta, advertiremos la redundancia que se presenta al adjetivar calificativamente los conceptos elementales ${ }^{12}$ de su contenido, ejercicio que desarrollará cada destinatario o intérprete según sea el caso, dando origen a una gama de posibles entendimientos sobre un mismo concepto. La expresión "estándar", en especial referencia al ámbito internacional que nos interesa, es invocada en un sinnúmero de potenciales contenidos diversos: como criterio, como buenas prácticas, como principio, como regla, norma, y con diversas funciones o roles: interpretativo, como base para fundar imperativos, como parámetro de medición de un determinado índice de satisfacción. Esto requiere ser clarificado, y en ciertos aspectos o materias, delimitado y diferenciado ${ }^{13}$, permitiendo limpiar conceptualmente esta

7 Pudiendo hacerse referencia a entidades como la Organización de Naciones Unidas (por sus siglas ONU), la Organización de Estado Americanos (por sus siglas OEA), la Organización del Tratado del Atlántico Norte (por sus siglas OTAN), entre otras. Benavides, María Angélica (2009) "El consenso y el margen de apreciación de los derechos humanos". Ius et Praxis, Vol. 15, N 1, p. 295.

$9 \quad$ Laporta, Francisco (1987) "Sobre el concepto de derechos humanos". Doxa. No 04, p. 24.

10 Pérez Luño, Antonio (1987) "Concepto y Concepción de los Derechos Humanos". Doxa, $\mathrm{N}^{\circ} 04$, p. 47.

11 Pérez Luño (1987) “Los Principios Generales del Derecho, ¿un mito jurídico?”. Revista de Estudios Politicos Nueva Época, No 98 , p. 59.

12 Calvinho, Gustavo (2015) "El Sintagma del debido proceso". Revista Derecho Ecuador, p. 1.

13 Como resultaría necesario en la protección a la niñez y adolescencia en conflicto con la Ley, donde se requeriría un estándar diferenciado del de los adultos debido a la condición de especial vulnerabilidad de los menores de edad tan solo por su edad, lo que llevaría a la necesidad de un sistema especial, que establezca garantías necesarias acorde a su condición de sujetos de derecho. Revisar en este sentido Alvarado (2010); Beloff (1998) y (2007); Cillero (2010); Duce y Couso (2010); Maldonado (2009). 
multiplicidad de significados usados en la práctica, resignificando el objetivo por el cual fueron creados, además de potenciar los derechos que pretenden asegurar.

Detectar estas diferentes interpretaciones y usos, y visualizar las posibles afectaciones en el ámbito del derecho, es el ejercicio que esperamos que el lector realice con la lectura de este artículo. Desnaturalizar el uso común y la ligereza jurídica con que se habla de estándares jurídicos internacionales, recordando la importancia de saber qué es lo que estamos invocando como imperativo internacional y cuál es su implicancia en el ámbito nacional, resulta ser un objetivo interesante de estudio, por ser un tópico un tanto descuidado por la doctrina, o no del todo explorado, siendo de poca discusión actual y superado por otros importantes temas o puntos de reflexión que resultan del análisis de la dinámica relacional entre derecho interno y externo, por citar algunos: la incorporación del derecho internacional al derecho nacional ${ }^{14}$; su validez y poder vinculante; jerarquía normativa ${ }^{15}$; límites y/o márgenes ${ }^{16}$; mecanismos de control ${ }^{17}$ entre otros. Estos tópicos, siempre vigentes, no serán foco en este artículo por creer necesario abstraerse a una etapa aún primaria, más conceptual y de integración valorativa. Se trata de trabajar sobre una correcta individualización de la semántica de la acepción estándares internacionales, y comprender en definitiva en qué consiste el rasgo diferenciador de los enunciados normativos que contienen esta frase, y cuáles serían sus consecuencias conexas. Establecer esta característica semántica permitiría enfrentar la relación entre el estándar en sí, y su criterio interpretativo e integración valorativa. En síntesis, no hay claridad sobre lo que es un estándar a modo conceptual, sus efectos, consenso en su valor vinculante, ni el conocimiento de las diversas posibilidades o ejemplos de su existen-

14 Vale la pena leer el interesante planteamiento de la profesora Fuentes, sobre el impacto que provoca la incorporación de normativa internacional al sistema nacional en su sentido crítico, en Fuentes, Ximena (2007) "El derecho internacional y el derecho interno: definitivamente una pareja dispareja". Revista de Economía y Derecho, Vol. 15, № 4, publicada por la Universidad Peruana de Ciencias Aplicadas, pp. 2-35.

15 Ver Doctrina del Bloque de Constitucionalidad y su relación con el Control de Convencionalidad en NúŃEz, Constanza (2015) "Bloque de constitucionalidad y Control de Convencionalidad en Chile: avances jurisprudenciales". Anuario de Derechos Humanos de la Universidad de Chile, № 11 pp. 157-169.

16 Sobre margen de apreciación como teoría para la incorporación del derecho internacional, limitado por el sistema normativo nacional, se puede profundizar en los siguientes autores nacionales y sus textos reseñados en bibliografía: NúŃEZ (2011); Contreras (2014): Benavides (2009); Peredo (2013); Martínez (2014).

17 Nogueira (2006) Ver doctrina del Control de Convencionalidad que nace como estándar entregado por la Corte IDH en el caso Almonacid v/s Chile en el año 2006, teniendo como principal exponente nacional al profesor Humberto Nogueira. Así también Salinas, J.P. (2013) Control de convencionalidad en el Sistema Interamericano de Derechos Humanos: Alcance y recepción a partir del deber de adoptar disposiciones de Derecho Interno. Colombia: Universidad Nacional. 
cia. Clarificar estos términos conlleva una complejidad importante que se esbozará en el capítulo final de este artículo. Por ahora, generar la reflexión es el objetivo.

\section{2) INTENTOS DE CONCEPTUALIZACIÓN}

Intentaremos, siguiendo algunos trabajos realizados en la doctrina analizada $^{18}$, entregar una primera definición de estándar internacional, entendiéndolo como: "un término de naturaleza valorativa, caracterizado por la indeterminación, por lo que su significado no es determinable salvo recurriendo a criterios, parámetros de juicio, internos y/o externos al derecho". Este concepto, si bien es una adaptación ${ }^{19}$, nos ilustra en sus características principales y nos sitúa en una primera problemática, la dificultad en determinar su significado, puesto que implica una elección entre criterios de juicio generalmente en competición. La integración valorativa resulta fundamental en este sentido, la cual resuelve en la elección del criterio útil para la determinación del significado. Si volvemos a la discusión planteada por Velluzzi y Chiassoni respecto a las cláusulas generales, y que utilizamos para este ejercicio comparativo, podríamos afirmar que la cláusula general es, efectivamente, un término valorativo y por lo tanto indeterminado y el estándar es el criterio de juicio por medio del cual se determina el significado de la cláusula general resolviendo la indeterminación ${ }^{20}$. No deja de ser interesante la posibilidad de utilizar el concepto de estándar internacional, como herramienta de concreción del propio derecho internacional o de los principios que emanan de sus instrumentos complementarios y que carecen de fuerza obligatoria.

Sin detenernos en los conceptos básicos de la $\mathrm{RAE}^{21}$ o el origen etimológico $^{22}$ de la palabra estándar, parece necesario retrotraernos al estudio gramatical de esta a través de la sintaxis del concepto estándar,

18 Chiassoni, Pierluigi (2011) "Las cláusulas generales, entre teoría analítica y dogmática jurídica”. Revista de Derecho Privado, No 21, pp. 89-106, citando a Velluzzi (2010) Le clausole generali. Semantica e politica del diritto. Milano: Quaderni di Filosofia Analitica, p. 1 y ss. Adaptación del concepto de cláusulas generales citado por ChIAssoni (2011) 90.

Chiassoni (2011) 100.

Según la RAE, se entenderá por estándar: "aquello que sirve como tipo, modelo, norma, patrón o referencia", lo que nos lleva a relacionarlo directamente con la forma y uso con que estamos habituados a usarla, sobre todo en el ámbito internacional, como modelo a seguir.

22 Curioso resulta su origen etimológico, por ser una palabra derivada del inglés "standard" (que a su vez se originó en el francés "standort", palabra integrada por "stand" que significa parado, $y$ "ort" = lugar alto, que es donde los francos colocaban su bandera para que no la tomaran los enemigos en la época de las invasiones bárbaras), la cual proviene de los vocablos "stand" y "hard", haciendo mención a la necesidad de mostrar fuerza ante el enemigo a través de los hoy conocidos "estandartes" que debían estar fuertemente erguidos en todo momento como señal de autoridad. Disponible en: http://etimologias.dechile.net/ 
identificando las características semánticas existentes en él, aspirando a valorar si de estas derivan ciertas consecuencias sobre el plano interpretativo y aplicativo ${ }^{23}$. Podemos acordar también que al referirnos a estándares internacionales, estamos hablando de un sintagma jurídico ${ }^{24}$, es decir, un conjunto de palabras que al interior del discurso jurídico tienen una función determinada. Ejemplos sobre los cuales se ha teorizado desde una perspectiva jurídico-gramatical, encontramos los conceptos de debido proceso $^{25}$, principios generales del derecho ${ }^{26}$, y de cláusulas generales $^{27}$, por nombrar algunos.

Si de conceptualizaciones hablamos, no podemos dejar de mencionar el concepto de estándar desarrollado en el marco del trabajo de la ISO ${ }^{28}$ que se ha trasformado en referencia obligatoria en el ámbito internacional en diferentes rubros y materias. Según la ISO: "Los estándares son acuerdos (normas) documentados que contienen especificaciones técnicas u otros criterios precisos para ser usados consistentemente como reglas, guías, o definiciones de características para asegurar que los materiales productos, procesos y servicios se ajusten a su propósito" ${ }^{29}$. Los estándares son construcciones culturales, efectuadas por quienes poseen autoridad ética, técnica, teórica o científica, según el caso, de público conocimiento que nos dan confianza en nuestro accionar, pues nos sirven de guía y referencia, y a posteriori permite controlar lo producido para realizar sobre ello un juicio de valor.

Pero, ¿qué es un concepto?, ¿por qué esta complejidad lingüística, multifacética, semántica, y/o cognoscitiva es tan importante? El ejercicio de mirar hacia el propio término concepto parece necesario y conocido. El diferenciar concepto de otras palabras como significado, concepción y definición no son precisiones ajenas al derecho, o al menos a la filosofía

23 Un valioso estudio en este sentido se realizó referente al término Cláusulas Generales por el profesor italiano Vito Velluzzi, encontrando importantes acercamientos y coincidencias con nuestro objetivo de estudio y la confusión en el uso de sintagmas jurídicos, señala en este sentido: "No toda cláusula general es un principio, y no todo principio es una cláusula general... VelLuzzi (2010) 74 ss.

24 Según RAE: Palabra o conjunto de palabras que se articula en torno a un núcleo y que puede ejercer alguna función sintáctica.

Calvinho (2015) 1 y ss.

Pérez Luño (1997) 9 y ss.

Velluzzi (2010) 1 y ss.; Chiassoni (2011) 1 y ss.

ISO es la sigla adoptada para identificar la International Organization for Standarization, organización internacional no gubernamental, creada coincidentemente en 1947 (post segunda guerra mundial) y con objetivos de promover el desarrollo de normas y regulaciones internacionales, garantiza calidad y seguridad en todos los productos, a la vez que se respetan criterios de protección ambiental. Se conoce por ISO tanto a la Organización de Estandarización Internacional, como a las normas establecidas por la misma para estandarizar los procesos de producción y control en empresas y organizaciones internacionales. 
del derecho. Dworkin ${ }^{30}, \mathrm{Hart}^{31}$, Kelsen ${ }^{32}$, $\mathrm{Kant}^{33}$ y Bobbio ${ }^{34}$, por nombrar algunos, han teorizado sobre el concepto de derecho y de principios, dándonos luces sobre interesantes puntos de partida a nuestro objetivo de estudio, como es la distinción entre concepto y concepción avanzada por Dworkin $^{35}$, la cual, reducida a la base de sus elementos, sitúa al concepto como el significado teórico y general de un término, en cambio la concepción sería la forma de llevar a la práctica un concepto ${ }^{36}$. En ese sentido, partiremos por generar reflexiones en torno al concepto, para dejar la concepción a un estudio más detallado.

Las definiciones ${ }^{37}$, sobre todo las ostensivas ${ }^{38}$, nos entregan un punto de partida para entender qué es un estándar en general, pudiendo hacer uso de analogías, experiencias y evidencias empíricas para la formación de un concepto. En este sentido, muchas veces son usados los estándares para la formación de normas obligatorias tanto nacionales como internacionales, sirviendo de marco y experiencia, tal como este tipo de definición lo indica. Lo peligroso está en la confusión, u homologación de lo que es un estándar, al contenido de una norma específica. No necesariamente deben comprenderse como sinónimos una norma internacional con el estándar internacional relativo a la aplicación de dicha norma. Así, no resultaría eficaz definir cuáles o qué son los derechos humanos, solo con mostrar la declaración universal ${ }^{39}$ de los mismos, sabiendo que el derecho y el "ser humano" son sistemas dinámicos y cambiantes, pudiendo a futuro esta declaración o catálogo necesitar ser actualizado, ya sea porque

30 Dworkin (1984) Ver Los derechos en serio (título original Taking Rights Seriously 1977) y su desarrollo de conceptos base como principios, normas y directrices. A su vez debemos recordar que, para este autor, la creación de derecho post-factum no es posible, pues viola las expectativas de quienes realizaron la acción esperando una determinada consecuencia jurídica. Importante este punto debido a la creación de derecho que se da a través de la judicatura, mediante el uso e interpretación de instrumentos internacionales, muchas veces invocados con el formato de "estándares".

31 HaRT (1994) ver El concepto de derecho (título original The Concept of law 1961).

32 Kelsen (1992) ver Teoría pura del derecho (título original Pure Theory of Law 1967).

33 Kant (2004) Principios metafisicos del derecho (título original "Metaphysische Anfangsgründe der Rechtslehre 1797).

34 Bоввіо (2002) ver Teoría general del derecho (título original Teoria Generale del Dirittto 1958) y su importante contribución a los elementos del concepto de derecho.

35 Pérez LuÑo (1987) 47 citando a Dworkin.

36 Pérez LuÑo (1987) 47.

37 Formación de un concepto. Proposición que expone con claridad y exactitud los caracteres genéricos y diferenciales de algo material o inmaterial (RAE).

38 Una definición ostensiva, es cuando el emisor puede realizar asociaciones basadas en la analogía o poner ejemplos concretos que son más gráficos y visuales para ayudar al receptor de ese mensaje a hacerse cargo de la idea. Esto se hace al parecer con los estándares, que se toman como ejemplos para la construcción de una norma.

39 Declaración Universal de los DDHH, disponible en: http://www.un.org/es/documents/ udhr/ 
se han resuelto en la sociedad algunas problemáticas ${ }^{40}$, o por la necesidad de incorporación de nuevos derechos ${ }^{41}$ debido a los cambios sociales.

Sea concretizar concepto o significado, parece necesario el trabajo sobre nociones fundamentales para la organización jurídica, conceptos como principios generales y cláusulas generales conforman una especie de pautas universales necesarias para dotar a las normas positivas de juridicidad, y por tanto de obligatoriedad. Siguiendo esta lógica, el concepto de estándar internacional no está cumpliendo del todo esta función de pauta universal o parámetro de exigencia, evitando la funcionalidad del concepto en su puesta en práctica, debido a la falta de estudio y desarrollo de los mismos, lo que sí podemos observar con el estudio y concretización de los principios generales del derecho ${ }^{42}$.

En otro paralelo de análisis, podríamos imaginar en el desarrollo del concepto de derecho, el cual es usado en diversos contextos que forman su significado, en los cuales pudiese ser un imperativo para la toma de fuerza de este concepto aplicado al ámbito jurídico, el principio de la correlación, según el cual, debe existir un deber para que exista un derecho, y a su vez, la existencia de una norma que comprenda tanto el derecho a garantizar, como el deber exigible a otro ${ }^{43}$.

Con los estándares jurídicos, podemos preguntarnos primeramente si son derecho y de qué forma entran a ser parte del sistema. Como normas, principios, crean obligaciones por su sola existencia, deben ser incorpo-

40 Como la erradicación de la esclavitud que, en nuestra sociedad occidental, de la forma primaria en que fue conocida, ya no existe. Por lo tanto, ya no es necesario relevarlo en la categoría de derecho humano y tampoco establecerlo como estándar.

41 Por citar ejemplos de incorporación o reclamación de nuevos derechos humanos, sucede con la arremetida de la tecnología, debido a la cual han emergido necesidades expresadas en derechos como el derecho a la verdad, a la privacidad y su reciente expresión, el derecho al olvido, relacionado a la eliminación de datos del internet, disponible en: http://www.derechoalolvido.eu/

42 Rodríguez, Sonia (2008) Los Principios Generales del Derecho. España: Editorial Universitaria Sur; y Pérez LuÑo (1997) realizan en sus obras, importantes reflexiones en torno al concepto de principios generales del derecho, cuestionando su ambigüedad, contrariedad, y generalidad. Rodríguez realiza una significativa recopilación de conceptualizaciones, inspirada en gran parte por el trabajo realizado una década antes por Pérez Luño, de cuya lectura, se obtendrán mayores motivaciones para la realización de un trabajo similar con el concepto de estándar internacional.

43 Como se deduce, es una referencia clara a la antigua confrontación entre iusnaturalismo y el iuspositivismo. Para Hobbes la existencia del derecho es inherente al ser humano y no depende de la positivización de los mismos, lo cual fue contrastado por Kelsen y Pufendorf, lo que nos puede graficar y recordar la interacción entre deber ser y el ser, y de esta forma su implicancia en la norma. Esto mismo puede suceder con el concepto de estándar, donde su sentido ontológico y axiológico se ven entremezclados y confusos. Ver Marcone, Julieta (2005) Hobbes: entre el iusnaturalismo y el iuspositivismo. México: Andamios, Vol. 1, N², p. 126 y LAPORTA (1987) 124. 
radas de forma vinculante al derecho interno ${ }^{44}$, para luego intentar hacer el link con el derecho internacional, determinando cuál es su sentido de existencia como regulador de la actividad de los Estados a través de herramientas que fijan estándares internacionales ${ }^{45}$, definiendo su contenido y alcance para efectos de su exigibilidad.

Ya que parte del problema o reflexión que queremos plantear está relacionado con el uso que el derecho internacional ha dado a este sintagma, no podemos dejar de mencionar los conceptos dados por organismos internacionales como la propia Comisión Interamericana de Derechos Humanos (CIDH), la cual define como estándares jurídicos "al conjunto de decisiones judiciales, informes temáticos y de pais, y otras recomendaciones adoptadas por la Comisión Interamericana de Derechos Humanos. El término "estándares jurídicos" asimismo se refiere a los tratados regionales de derechos humanos que gobiernan el sistema interamericano, como la Convención Americana y la Convención de Belém do Pará. El concepto igualmente se refiere a las sentencias y opiniones consultivas emitidas por la Corte Interamericana de Derechos Humanos"ł6. Esta definición deja aún más en evidencia la urgente necesidad de concreción, puesto que si todo, absolutamente todo se entenderá como estándar, entonces, ya no habría nada que estandarizar, o dicho de otro modo, no existirá límite, entre el contenido de la norma principal y de su respectivo estándar.

La pretensión de fijar conceptos se hace en la práctica inviable cuando se proyecta sobre nociones tales como la de «derecho» o «derechos humanos» ya que estos términos han sido y son utilizados en múltiples y diferentes contextos lingüísticos alejados en el tiempo y en el espacio ${ }^{47}$. Lo mismo aplicaría entonces en la elaboración de un concepto único de estándar, sabiendo que la interpretación de la indeterminación de su contenido no es una tarea que se resuelva con un concepto teórico o estructural, o estipulativo. Los conceptos o definiciones no son tajantemente correctos o falsos, se deben adecuar a la realidad y por sobre todo a la finalidad, cobrando vital importancia la relación entre la indeterminación y el ejercicio de integración valorativa ${ }^{48}$ que se requiera por deber entregar un contenido subjetivo o interno al momento de valorizar estas definiciones. Estas por tanto, serían expresiones valorativas, cuyos signi-

\footnotetext{
44 Albanese, Susana (2008) "La internacionalización del derecho constitucional y la constitucionalización del derecho internacional". Albanese, Susana (coordinadora): El control de convencionalidad. Buenos Aires: Editorial Ediar, pp. 13-45.

45 Cabe recordar nuevamente a Kelsen, quien nos advierte no confundir Derecho con justicia, en Kelsen (1992) 21.

46 Definición entregada por la $\mathrm{CIDH}$ a propósito del informe que entrega estándares jurídicos vinculados a la igualdad de género y derechos de la mujer en el sistema interamericano, sobre los cuales se hará mayor referencia en el capítulo siguiente.

47 Pérez LuÑo (1987) 49

48 Chiassoni (2011) 92.
} 
ficados no pueden ser determinados sin hacer referencia a un conjunto de parámetros jurídicos, morales, sociales, de un arte, de una técnica, de una ciencia, o de una disciplina, por estos referidos ${ }^{49}$. Es decir, fijaremos el contenido de un estándar en base a los criterios que se hayan definido para esto, los cuales ciertamente están propensos al cambio, y es en este dinamismo donde observamos la dificultad en concretizar el contenido del sintagma estándar internacional, puesto que el criterio escogido para apoyar su definición, puede variar con el tiempo o simplemente puede no haber sido determinado ${ }^{50}$. No es posible entregarle a una premisa la esencia de las cosas, sabemos que en función de los usos lingüísticos se obtendrán al menos dos significados, el habitual del término en sí, y el que adquiere como concepto jurídico ${ }^{51}$. El peligro de crear conceptos solo on the books y no in action, es un riesgo que debe ser evitado o subsanado, siendo la primera tarea el estudio de los usos actuales y sus potenciales contenidos a través de una indagación conceptual, lo más rigurosa posible.

Si pudiésemos afirmar que los estándares internacionales son establecidos e invocados por los organismos internacionales con un objetivo específico, que busca impactar en los sistemas jurídicos nacionales, especial cuidado debiésemos tener con el uso de esta terminología ya que mediante la ampliación semántica se corre el riesgo de convertir el concepto en sinónimo de todo lo que emana del derecho internacional lo que puede conllevar a un desvío significativo del objetivo establecido. La noción de estándar parece por sí misma demandar ciertos elementos estructurales y formales que podrían ser analizados y tomados en cuenta al momento de determinar su contenido, no necesariamente definirlos, lo cual es de extrema complejidad por su contenido valórico e individualizable, pero sí podemos pensar en determinar su contenido de manera de poder usarlo como criterio o herramienta en la operativización del derecho internacional al interior de los Estados.

No todo estándar es norma ni toda norma es estándar. Esto nos parece la premisa resumen para abordar la forma de tratamiento actual dada desde el ámbito internacional, definiendo de una vez por todas los estándares como principios inspiradores o mínimos exigibles, o simplemente como la totalidad del texto a obedecer (tratado regla, etc.). Un primer punto de partida puede ser la delimitación de este concepto para una esfera particular de protección.

\footnotetext{
49 Scarpelli, Uberto (1962) Filosofia analitica, norme e valori. Milano: Editorial Comunità, pp. 56-57.

50 Chiassoni (2011) 92

51 Pérez LuÑo (1997) 9.
} 
Apuntamos hacia la necesidad de conceptualización de un estándar internacional ${ }^{52}$ generando primeramente discusión doctrinaria y reflexión en torno al tema, pudiendo tomar como referencia la necesidad levantada en su momento respecto a los conceptos de principios generales o cláusulas generales que obligaron a la doctrina a abordar ampliamente el tópico, requiriendo una importante actividad intelectual que delimitó su ámbito de acción y clarificó a los operadores en su uso específico.

En este proceso no debemos limitarnos o estancarnos en la indeterminación del concepto, evitando caer en la generalización cuando un concepto es complejo de determinar, puesto que esta indeterminación necesariamente llevará a una integración valorativa por parte de un intérprete, lo que no es del todo fácil ni menos riesgoso, sobre todo cuando el intérprete final termina siendo un juez que debe aplicar derecho o hacer justicia. Ante esto se propone mayor desarrollo doctrinario al respecto, pudiendo apoyar a los actores en la ejecución y operativización del concepto de estándar internacional, sobre todo teniendo en cuenta la masificación de su uso en el ámbito del derecho internacional de los derechos humanos. Debemos advertir en este camino, la clara diferencia entre la conceptualidad de un estándar y la materialidad de la estandarización, teniendo siempre en cuenta la necesidad de volver a las obras esenciales del derecho, lo cual debiese estar presente en toda construcción jurídica, ya sea doctrinaria o normativa, con su necesaria cuota de originalidad y creación, sin descuidar la consulta a los textos base, a los primeros filósofos del derecho, aquellos muchas veces olvidados por la especificidad de la literatura y la necesidad de destacar a través de lo novedoso. Es sorprendente ver cómo los problemas actuales fueron abordados en otros tiempos seguramente con otro catalizador o forma de manifestación, pero su esencia puede servirnos en la resolución presente.

Generada la reflexión sobre la complejidad que conlleva la falta de concretización y diversidad en los usos de la palabra estándar, se entrega a modo de síntesis y de manera gráfica, una tabla con los principales usos que hoy en día se entregan a la palabra "estándar" en el ámbito jurídico internacional, con algunos ejemplos en pie de página:

\footnotetext{
52 Podemos pensar también en general estandarización de contenidos, como ocurre en otros ámbitos de la comunidad internacional. Para esto podemos partir con revisar estas experiencias sobre todo en los aspectos a considerar para el desarrollo de estándares, como son el consenso, la representatividad, etc. Ver cómo el organismo internacional ISO desarrolla estándares. Disponible en: http://www.iso.org/iso/home/standards_development.htm
} 


\section{TABLA 1: \\ Usos de la palabra 'estándar'}

\begin{tabular}{|l|l|}
\hline \multicolumn{1}{|c|}{ Concepto } & \multicolumn{1}{c|}{ Significado (RAE) } \\
\hline Principio $^{53}$ & Norma o idea fundamental que rige el pensamiento o la conducta. \\
\hline Regla $^{54}$ & Aquello que ha de cumplirse por estar convenido en una colectividad. \\
\hline Directriz $^{55}$ & Instrucción o norma que ha de seguirse en la ejecución de algo. \\
\hline Lineamiento $^{56}$ & Dirección, tendencia. Rasgo característico de algo. \\
\hline Derecho $^{57}$ & $\begin{array}{l}\text { Conjunto de principios y normas, expresivos de una idea de justicia y } \\
\text { de orden, que regulan las relaciones humanas en toda sociedad y cuya } \\
\text { observancia puede ser impuesta de manera coactiva. }\end{array}$ \\
\hline Criterio $^{58}$ & Norma para conocer la verdad. Juicio o discernimiento. \\
\hline Buena práctica & $\begin{array}{l}\text { Toda experiencia que se guía por principios, objetivos y procedimientos } \\
\text { apropiados o pautas aconsejables que se adecuan a una determinada } \\
\text { perspectiva normativa o a un parámetro consensuado, así como también } \\
\text { toda experiencia que ha arrojado resultados positivos, demostrando su } \\
\text { eficacia y utilidad en un contexto concreto }\end{array}$ \\
\hline Declaración
\end{tabular}

53 "Principio del interés superior del niño "consagrado en el artículo No3 de la CDN.

"Principios de Yogyakarta "Principios sobre la aplicación de la legislación internacional de derechos humanos en relación con la orientación sexual y la identidad de género adoptados el año 2006”. Disponible en: http://www.yogyakartaprinciples.org/principles_sp.pdf

54 "Reglas mínimas de las Naciones Unidas para la administración de la Justicia de menores" adoptadas por la Asamblea General en su resolución 40/33, de 28 de noviembre de 1985 . "Reglas de las Naciones Unidas para la protección de los menores privados de libertad" adoptadas por la Asamblea General en su resolución 45/113 de 14 de diciembre de 1990. "Directrices de las Naciones Unidas para la prevención de la delincuencia Juvenil" adoptadas y proclamadas por la Asamblea General en su resolución 45/112, de 14 de diciembre de 1990.

56 "Lineamientos para la protección al consumidor en el contexto del comercio electrónico". Recomendaciones del consejo de la OCDE (Organización para la Cooperación y el Desarrollo Económico) Disponible en: http://www.oecd.org/internet/consumer/34023784.pdf

57 En este sentido sirve de ejemplo toda referencia a Derechos humanos entendida como estándar internacional, partiendo por la Declaración Universal de los DDHH. Disponible en: http://www.un.org/es/documents/udhr/

58 Los criterios de interpretación consagrados en la Convención de Viena, pueden considerarse reglas de derecho internacional general. Disponible en: http://www.oas.org/36ag/espanol/ doc_referencia/Convencion_Viena.pdf Además ver Opinión Consultiva de la CIDH OC3/83 del 8 de setiembre de 1983 punto No47. Disponible en: http://www.corteidh.or.cr/ docs/opiniones/seriea_03_esp.pdf

59 "Declaración de Arusha sobre buenas prácticas penitenciarias". Disponible en: https://www. unodc.org/pdf/criminal_justice/Compendium_UN_Standards_and_Norms_CP_and_CJ_ Spanish.pdf

60 No existe significado compuesto en la RAE, visto en http://www.paho.org

61 "Declaración de Viena sobre la delincuencia y la justicia frente a los retos del siglo XXI"; "Declaración de principios y programas de acción del Programa de las Naciones Unidas en materia de prevención del delito y justicia penal"; "Declaración sobre la eliminación de la violencia contra la mujer" entre otras, todas disponibles en Recopilación de reglas y normas de las Naciones Unidas en la esfera de la prevención del delito y la justicia penal. Disponible en: https://www.unodc.org/pdf/ criminal_justice/Compendium_UN_Standards_and_Norms_CP_and_CJ_Spanish.pdf 


\section{3) ALGUNAS REFERENCIAS A ESTÁNDAR}

A modo de confirmar y ejemplificar la afirmación anterior sobre la falta de concretización de un concepto de estándar, en esta sección se proporcionarán y discutirán algunas de las referencias usadas y conocidas del concepto estándar internacional, tanto a nivel nacional como internacional. A este respecto es importante destacar que si bien en el ámbito internacional múltiples son las referencias que se hacen al término estándar internacional ${ }^{62}$, la interiorización de este a los sistemas nacionales se ha llevado a cabo sin mayor reflexión. Por otra parte, en este capítulo se expondrá en detalle algunas de estas referencias dejando en evidencia la multiplicidad lingüística antes enunciada, las diferencias de interpretación y los efectos de esta ampliación semántica con el objetivo de llevar al lector a reflexionar sobre los argumentos planteados por la autora del presente artículo.

Parece inevitable partir con las referencias realizadas por la Corte $\mathrm{IDH}^{63}$ al término estándares jurídicos internacionales en derechos humanos. Esta Corte es una de las principales creadoras de estándares a través de su jurisprudencia ${ }^{64}$, entre los cuales se destacan los estándares del debido proceso, ampliamente estudiados por la doctrina, ya sea como criterios $^{65}$, o como estándares propiamente tal ${ }^{66}$. De su lectura podemos evidenciar la falta de precisión en su invocación, siendo demasiado amplios para ser exigibles como mínimo esperado, su redacción con manto de autoridad y obligatoriedad dado por la Corte, pero al mismo tiempo su dilución en los mecanismos efectivos de controlar su cumplimiento, pues queda aún la duda si un estándar entregado por la Corte IDH es norma obligatoria incorporada al derecho interno a través de las facultades inter-

62 Si bien no pertenecen al ámbito jurídico en sí, cabe destacar la labor realizada por un organismo internacional relacionado a la creación de estándares como es la ONUDI (Organización de las Naciones Unidas para el Desarrollo Industrial, UNIDO en inglés) http://www. unido.org/unido-united-nations-industrial-development-organization.html, la cual ayuda a los Estados miembros y a sus industrias con el cumplimiento de muchos de los estándares internacionales ya definidos. Esto incluye el cumplimiento de los estándares comerciales, métodos de prueba y metodología con el fin de participar en el comercio internacional. Algunos ejemplos son los estándares sobre la higiene de los alimentos y su seguridad alimentaria (ISO 22000), estándares internacionales de sistemas tales como la gestión de la calidad (ISO 9001), la gestión ambiental (ISO 14001), y la responsabilidad social (SA 8000).

63 Corte Interamericana de Derechos Humanos. Disponible en: http://www.corteidh.or.cr/

64 Ver casos de estándares de reparación confeccionados por la Corte Interamericana en el contexto colombiano. Escobar Martínez y otros (2011) 168.

65 García Ramírez, Sergio (2012) El debido proceso, criterios de la jurisprudencia interamericana. México: Editorial Porrúa, p. 9.

66 Ver estudio de los estándares fijados por el Sistema Interamericano de Derechos Humanos en relación al acceso a la justicia en los derechos económicos sociales y culturales, realizado por la CIDH. Disponible en: http://www.cidh.org/countryrep/AccesoDESC07sp/Accesodesciv.sp.htm 
pretativas de la Corte sobre la $\mathrm{CADH}$, o son meras declaraciones de principios con términos laxos como "recomendar" "promover" o "alentar", los cuales trasforman el contenido jurídico de un estándar a una categoría de mera recomendación ${ }^{67}$. Con una clarificación de cuáles serían normas internacionales y cuáles estándares de la misma, sería posible por un lado reducir la creación normativa y por otra parte reforzar el cumplimiento de los derechos con las ya diversas herramientas existentes.

Un ejemplo claro y primordial en este sentido parece ser lo que sucede con la Convención de los Derechos del Niño ${ }^{68}$, frecuentemente comprendida como un estándar en sí mismo, el cual estaría enfocado a dar un tratamiento especial a una categoría de sujeto específico que por su condición de vulnerabilidad reviste una necesidad de protección especial. A pesar de que su contenido es amplio y de gran alcance, continúa la tendencia a la creación de instrumentos complementarios, cuyos objetivos no son distintos a los de la propia Convención. Más en concreto aún, podemos concentrarnos en la relación de los niños y la justicia, y cuáles serían los estándares proclamados por la comunidad internacional respecto a esta interacción. En este punto, de especial relevancia a mi parecer por haberse creado un sistema especial en muchos países debido a la exigencia de adecuación de la normativa interna al derecho internacional, se hace más que necesario concretizar la no poco frondosa gama de normas relativas a esta relación niñez-delito. Solo por nombrar algunos, se han enunciado como estándar lo establecido en algunos artículos de diferentes cuerpos normativos internacionales como son la $\mathrm{CADH}^{69}$ y la $\mathrm{CDN}^{70}$, además de instrumentos especiales para esta materia ${ }^{71}$ como las

67 Se hace mención a esto, en virtud de la soberanía propia de los Estados, la cual no se pierde por la suscripción y posterior ratificación del tratado celebrado ante otros estados o ante organismos internacionales, ahora bien, dicho incumplimiento evidentemente supone falta de seguridad jurídica en el Estado faltante, no obstante, dicha consecuencia jurídica no es objeto de estudio del presente artículo.

68 Aprobada por la Asamblea General de las Naciones Unidas el 20 de noviembre de 1989, y ratificada por Chile el año 1990. Disponible en: http://unicef.cl/web/convencion/

69 Artículo 5.5: Cuando los menores puedan ser procesados, deben ser separados de los adultos y llevados ante tribunales especializados, con la mayor celeridad posible, para su tratamiento; Artículo $\mathrm{N}^{\circ}$ 19: Todo niño tiene derecho a las medidas de protección que su condición de menor requieren por parte de su familia, de la sociedad y del Estado.

70 Ver texto íntegro del artículo $\mathrm{N}^{\circ} 40$ de la CDN, que trata ampliamente los derechos y especiales consideraciones respecto de los menores de edad que sean acusados de la comisión de ilícitos penales.

71 Reglas de Beijing, Reglas de Tokio y Directrices de la Riad son comúnmente nombradas como estándares internacionales en materia de justicia juvenil, lo cual deja una puerta abierta a una amplia gama de posibilidades al momento de aplicar el derecho concreto. Concretizar que parte de estos instrumentos serán parte del estándar mínimo exigido le dará mayor fuerza y capacidad de exigibilidad a las normas internacionales de protección de los menores de edad en conflicto con la Ley Penal. 
Reglas de Beijing ${ }^{72}$, Reglas de Tokio ${ }^{73}$, y Directrices de la $\operatorname{RIAD}^{74}$. ¿Qué sucede con las opiniones consultivas ${ }^{75}$ de la Corte IDH, o las observaciones generales $^{76}$ emitidas por el CIDH? ¿Podemos entender que sus amplios textos son un estándar? ¿Es unánime que los tribunales nacionales las incorporen como derecho nacional, y por ende se utilicen más que como meras recomendaciones a los Estados? Al analizar estas normas referidas a la justicia juvenil podemos identificar solo una gran dispersión de información respecto a un punto focal en particular: no olvidar que para el derecho internacional un menor de edad que está cometiendo un delito sigue siendo un nińo, nińa o adolescente y por tanto debe respetársele esa calidad asegurando su desarrollo en las circunstancias en las que se encuentre. Esto parece difuminarse entre la parrilla de instrumentos internacionales que se han desarrollado para "alentar" a los Estados a lograr estos objetivos, careciendo muchas veces de la fuerza obligatoria necesaria y se termina tratando materias de vital importancia en formato de reglas o recomendaciones. Realizar una abstracción e integración de todos estos instrumentos, elaborando un "estándar internacional" único y exigible, sería una eficaz y práctica herramienta para los actores del sistema de justicia juvenil ${ }^{77}$.

En esta búsqueda de referencias en el ámbito internacional a la acepción estándares, ya hemos mencionado someramente los establecidos por el Sistema Interamericano de Derechos Humanos, SIDH $^{78}$, el cual no solo ha reconocido la necesidad de comenzar a delinear principios y

72 Reglas mínimas de las Naciones Unidas para la administración de la justicia de menores, adoptadas por la Asamblea General en su resolución 40/33, de 28 de noviembre de 1985. Disponible en: http://www.ohchr.org/SP/ProfessionalInterest/Pages/BeijingRules.aspx Reglas mínimas de las Naciones Unidas sobre las medidas no privativas de la libertad, adoptadas por la Asamblea General en su resolución 45/110, de 14 de diciembre de 1990. Disponible en: https://www.cidh.oas.org/PRIVADAS/reglasminimasnoprivativas.htm

74 Directrices de las Naciones Unidas para la prevención de la delincuencia juvenil, adoptadas y proclamadas por la Asamblea General en su resolución 45/112, de 14 de diciembre de 1990. Disponible en: https://www.cidh.oas.org/PRIVADAS/directricesdeRiad.htm

75 De especial relevancia la opinión consultiva OC-17/2002 de 28 de agosto de 2002, sobre la Condición Jurídica y Derechos Humanos del Niño.

76 En materia de justicia juvenil la observación general CRC/C/GC/10 del 25 de abril de 2007, sobre Los Derechos del Niño en la Justicia de Menores.

77 En Chile establecido por la Ley $\mathrm{N}^{\circ} 20.084$ de junio del 2007. Disponible en: http://www. leychile.cl/Navegar?idNorma $=244803$

78 SIDH, por el cual entendemos el conjunto de instrumentos y organismos tendientes a la protección de los $\mathrm{DDHH}$, fundados a raíz de la Convención Americana de Derechos Humanos (1978) e inspirada en la Declaración Americana de los derechos y deberes del hombre, primer instrumento internacional relativo a los DDHH. Sus pilares son la CIDH y la Corte IDH, contando con un gran dossier de documentos básicos los cuales pueden ser consultados en el siguiente link:

http://www.oas.org/es/cidh/mandato/documentos_basicos.asp 
estándares ${ }^{79}$ de diversos ámbitos, sino que también ha realizado referencias importantes sobre el uso de nuestro concepto de análisis. Uno de sus principales documentos relacionados son los estándares establecidos para el acceso a la justicia ${ }^{80}$ y el reciente informe emanado por la CIDH sobre la Universalización del Sistema Interamericano de $D D H H^{81}$ cuyo vínculo de acceso directo dentro de la página oficial de la Comisión es justamente donde aparece la palabra "Estándares". Este documento hace referencia expresa, en el capítulo 2 letra c, al tema de los estándares, en específico a los "Desafíos en la incorporación de estándares interamericanos a nivel interno" 82 , donde si bien no se da una conceptualización de los mismos, se hace constante referencia a ellos. Especial énfasis se da a la contribución que ha significado para ciertos Estados el establecimiento de estos estándares a distintos niveles tales como la fijación de criterios de fiscalización, protección y participación con ciertos sectores de la sociedad, y su funcionamiento como guía para el actuar político de algunos Estados ${ }^{83}$. En este mismo sentido, y analizando esta vez los estándares para el acceso a la justicia, podemos nuevamente ver contenidas las funciones de guía, control y trasparencia de los estándares dentro de un Estado, al leer el rol u objetivo que se les da en este informe: Estos estándares no solo tienen un importante valor como guía de interpretación de la Convención Americana sobre Derechos Humanos ("Convención Americana", "Convención" o "CADH") para los tribunales nacionales, sino que pueden contribuir a mejorar la institucionalidad de las politicas y servicios sociales en los paises americanos, y a fortalecer los sistemas de fiscalización, transparencia y rendición de cuentas, asi como los mecanismos de participación y vigilancia social de las politicas públicas en esta materia ${ }^{84}$.

Tanto la CIDH como la Corte IDH en su jurisprudencia han tendido a la creación de estándares internacionales en diversas materias, siendo luego promovidos como algo asumido con obviedad y claridad. Sin embargo, se presentan a su vez referencias en sentido negativo a su

$\mathrm{CIDH}$ "El acceso a la justicia como garantía de los derechos económicos, sociales y culturales. Estudio de los estándares fijados por el sistema interamericano de derechos humanos" OEA/ Ser.L/V/II.1 p.8.

CIDH "El acceso a la justicia como garantía de los derechos económicos, sociales y culturales. Estudio de los estándares fijados por el sistema interamericano de derechos humanos" OEA/ Ser.L/V/II.129 del 07 de septiembre del 2007. Disponible en: http://www.cidh.org/pdf\%20 files/ACCESO\%20A\%20LA\%20JUSTICIA\%20DESC.pdf CIDH "Universalización del sistema Interamericano de DDHH", OEA/Ser.L/V/II.152 Doc. 2114 agosto 2014. Disponible en: http://www.oas.org/es/cidh/informes/pdfs/Universalizacion-sistema-interamericano.pdf

$82 \mathrm{CIDH}$ "Universalización del sistema Interamericano de DDHH", OEA/Ser.L/V/II.152 p.28.

$83 \mathrm{CIDH}$ "Universalización del sistema Interamericano de DDHH", OEA/Ser.L/V/II.152 p.31.

CIDH "El acceso a la justicia como garantía de los derechos económicos, sociales y culturales. Estudio de los estándares fijados por el sistema interamericano de derechos humanos" OEA/ Ser.L/V/II.129 p.1. 
creación, es decir, a la no concreción de un estándar en cierta materia, dejando la duda sobre cuál es el mecanismo dentro del SIDH para la creación de los mismos, su relación de obligatoriedad con los Estados y su relación con otros conceptos jurídicamente relevantes. Podemos citar a modo de ejemplo un párrafo del informe anteriormente mencionado sobre el estudio de estándares referidos al acceso a la justicia que en este sentido refiere: A pesar de no poder afirmarse aun la existencia de un estándar definitivamente establecido en este punto, la jurisprudencia de la CIDH da cuenta de un principio de toma de posición del SIDH en la materia ${ }^{85}$. ¿No se concretó un estándar, pero sí un principio y toma de posición de un entero sistema?

Pasando al plano nacional, una de las recopilaciones nacionales más importantes sobre la situación de los derechos humanos en Chile hace referencia al informe anual del INDH ${ }^{86}$, el cual hace menciones directas y reiteradas al concepto de estándar las cuales no dejan de ser interesantes de analizar. Dentro de estas menciones se encuentran: la determinación de incorporación de estándares en las discusiones parlamentarias ${ }^{87}$, la equiparación del concepto de estándares internacionales de derechos humanos a elementos como el principio de reserva legal ${ }^{88}$, la normativa internacional como tratados y convenciones a criterios de la Corte $\mathrm{IDH}^{89}$, evidencia deudas e insuficiencias del Estado de Chile por no cumplimiento de estándares ${ }^{90}$, entre otros. Frases como: "Los principales estándares internacionales a considerar provienen de disposiciones contenidas en los diversos instrumentos juridicos internacionales de derechos humanos" pudiesen invitarnos a la ambigüedad y ligereza del discurso al hablar de "principales" estándares (sin decir cuáles serían estos para diferenciarlos de los no principales), o al referir "diversos" instrumentos jurídicos internacionales pudiendo caber toda norma o instrumento internacional sin distinción alguna. Si fuese así ¿cuál es la razón de que existan estándares si la completa norma internacional es el estándar?; o dicho de otro modo, ¿queremos ampliar el concepto de estándar jurídico internacional de tal forma que se confunda con la propia normativa en la que debe

$85 \mathrm{CIDH}$ "El acceso a la justicia como garantía de los derechos económicos, sociales y culturales. Estudio de los estándares fijados por el sistema interamericano de derechos humanos" OEA/ Ser.L/V/II.129 p.5.

86 Instituto Nacional de Derechos Humanos, corporación autónoma de derecho público creada por la Ley 20.405 el año 2009 y que comenzó sus funciones de promoción y protección de los DDHH en julio del 2010. Último informe disponible en http://www.indh.cl/informe-anual-situacion-de-los-derechos-humanos-en-chile-2014

$87 \quad$ Informe anual INDH (2014) 9.

$88 \quad$ Informe anual INDH (2014) 29.

89 Informe anual INDH (2014) 11, 24, 25.

90 Informe anual INDH (2014) 42, 43, 45, 47. 
su concreción? ${ }^{91}$. Pareciera ser simple reducir el concepto de estándar jurídico internacional a los distintos instrumentos internacionales, pero claramente esto haría perder el sentido de la existencia de un estándar, entendiéndose este como la creación de un marco de acción mínimo que garantice la protección a determinados derechos y/o garantías, los cuales han sido priorizados por las características especiales que estos revisten. No queremos decir con esto que estamos a favor de la teoría de la jerarquización de los derechos, pero sí debemos cuestionarnos al menos la validez, legitimidad y fuerza obligatoria que pierden las materias de derechos humanos cuando todo se convierte en algo de primera importancia y se vuelve un estándar de comportamiento para los Estados, ante lo cual su efectivo cumplimiento se hace evidentemente difícil. Una solución parece ser la selección de artículos dentro de un mismo instrumento normativo internacional, que dirija a la sociedad a desmenuzar el contenido, para rearmar su espíritu en forma de estándar ${ }^{92}$. De esta forma mantendríamos el carácter de especialidad, importancia y universalidad de los derechos humanos, sin desgastar su fuerza obligatoria debido a un uso extensivo y difuso ${ }^{93}$.

Pasando a otro ámbito, la $\mathrm{CIDH}^{94}$ ha desarrollado estándares en diversas materias y con distintos adjetivos. Es así que queremos destacar los estándares jurídicos desarrollados por este organismo vinculados a la igualdad de género y los derechos de las mujeres, los cuales vienen desarrollándose hace ya varios años y cuya última actualización ya fue publicada este ańo $2015^{95}$. En este informe podemos encontrar referencias explícitas al concepto de estándar, y más aún, en un intento de dotarlos de fuerza obligatoria se les cataloga de jurídicos. Una referencia directa a este necesario poder vinculante evidenciado además como ausente por la propia CIDH puede desprenderse del texto del informe en el siguiente párrafo del resumen ejecutivo: La Comisión ha destacado como el desarrollo jurídico de estándares en el marco del sistema interamericano de derechos humanos debe estar acompañado por esfuerzos de los Estados de ponerlos en práctica. A su vez, la CIDH ha identificado como un componente clave de estos esfuerzos la garantía de un acceso de jure y de facto a recursos judiciales idóneos y efectivos para superar problemas emblemáticos como la discrimi-

91 Por dar un ejemplo, ¿cuál sería el estándar para la protección de los menores de edad privados de libertad, ¿̇todas las reglas, observaciones, opiniones consultivas, sentencias, protocolos, tratados y convenciones existentes sobre la materia? ¿Para qué crear entonces un estándar?

92 Informe anual INDH (2014) 72-73

93 Laporta, Francisco (1987) "Sobre el concepto de derechos humanos". Doxa, No 04, p. 24.

94 Comisión Interamericana de Derechos Humanos. Disponible en: http://www.oas.org/es/ cidh/

95 Disponible en: https://www.oas.org/es/cidh/informes/pdfs/EstandaresJuridicos.pdf 
nación y la violencia contra las mujeres ${ }^{96}$. Como podemos observar, se termina apelando al esfuerzo de los Estados para lograr una efectiva ejecución de los estándares, lo cual será de real complejidad considerando la amplitud de lo que comprende por estándares internacionales la $\mathrm{CIDH}$ para este informe ${ }^{97}$. Complejo resultaría además, con un concepto así de amplio, el cumplimiento de los objetivos planteados para este informe ${ }^{98}$, entre los cuales está promover el uso y desarrollo de estándares, y crear una herramienta de ejemplificación de la aplicación de los mismos. Sería como pedir a cada Estado que creara normas, jurisprudencia y observaciones internacionales.

Complejo resulta además el uso dado en algunas materias por la propia CIDH al concepto en análisis, donde nos encontrarnos como referencia a "estándares del sistema interamericano de DDHH" una remisión a la totalidad de las normas del sistema, siendo confuso y desalentador para los Estados miembros de la OEA usar como guía estos parámetros en el cumplimiento de sus obligaciones ${ }^{99}$. Utiliza además sistematizaciones de "estándares" para ciertas materias lo que deja en evidencia la amplitud, subjetividad de interpretación y de construcción de los mismos ${ }^{100}$. Europa en cambio, pudiese ser quien más adelanto tiene al momento de establecer estándares de aplicación común a los Estados de la Unión, a través de múltiples procesos de armonización ${ }^{101}$ y en diversas áreas del derecho ${ }^{102}$. Su uso práctico y la medición de resultados resulta aún des-

$\mathrm{CIDH}$, Acceso a la Justicia para las Mujeres Víctimas de Violencia en las Américas, OEA/ Ser.L/V/II. Doc. 68, 20 de enero de 2007, párr. 1.

97 Ver concepto citado en página 8 cita $\mathrm{N}^{\circ} 45$ de este artículo.

98 Los objetivos del informe sobre estándares jurídicos en materia de igualdad de género de la CIDH son: Primero, analiza y sistematiza sentencias judiciales que aplican de forma explícita en sus consideraciones y su resolución los estándares del sistema interamericano de derechos humanos emitidos para avanzar la igualdad de género y los derechos de las mujeres. Segundo, tiene como propósito promover con este análisis el uso continuo de los estándares del sistema interamericano de derechos humanos por los poderes judiciales de la región. Tercero, intenta crear una herramienta y ejemplificar para diversos sectores el uso de los estándares del sistema interamericano de derechos humanos en el avance de la igualdad de género y los derechos de las mujeres. Cuarto, procura contribuir al desarrollo consistente de estándares jurídicos por parte de los órganos del sistema interamericano de derechos humanos. En quinto lugar, la CIDH tiene como un objetivo prioritario el apoyar a los Estados Miembros de la OEA en el cumplimiento de sus obligaciones de derechos humanos en la esfera de la igualdad de género y los derechos de las mujeres.

"Estándares Jurídicos en igualdad de género de la CIDH" OEA/Ser.L/V/II.143 actualización 2011 al 2014 p. 18.

100 "Estándares Juridicos en igualdad de género de la CIDH" OEA/Ser.L/V/II.143 actualización 2011 al 2014 p. 19 y 74.

101 Un análisis de los procesos de armonización europeos relativos al derecho penal en CARNEVALI (2009) 183 y ss.

102 Alonso GonzÁlez, Luis M. y otros (1997) La armonización fiscal en la Unión Europea. Centro de Estudios de Derecho, Economía y Ciencias Sociales. Barcelona: Editorial SL, p. $20-26$. 
conocido, pudiendo ser interesante analizar el resultado de la aplicación directa de los procesos de armonización a los Estados que son parte de la Unión Europea.

Desde la doctrina podemos evidenciar ejemplos de la falta de consenso a la hora de interpretar el uso de los instrumentos internacionales como estándares ${ }^{103}$, dándonos cuenta que la doctrina opera de manera similar aun en latitudes y culturas jurídicas diversas.

\section{4) CONCLUSIONES}

Las múltiples acepciones e intereses con que es invocado el sintagma jurídico estándar internacional, parecen restarle claridad y eficacia en relación a los fines para los cuales fueron creados. La necesidad de una adecuada conceptualización es la propuesta, la cual debiese tener como efecto principal saber el cuándo y para qué de su aplicación, pudiendo de esta forma identificar la función que cumplen en torno al derecho internacional, y para el caso de las materias específicamente exploradas en este artículo, definir su función en torno a los DDHH. Ya no es el foco del problema el dotarlos de una base de legitimidad o mayor fuerza obligatoria. Es, al contrario, la multiplicidad de sus usos adheridos a un poder vinculante inherente al derecho internacional, lo que nos obliga a buscar la operatividad del concepto.

Este desarrollo puede servir tanto a la formación de una nueva doctrina al respecto, como a la creación y entrega de guías técnico jurídicas a los operadores del sistema de justicia en torno a buscar el sentido estrictamente jurídico de la invocación de un estándar internacional, sabiendo que estamos ante un sintagma jurídico que requeriría ser integrado y aplicado, separado de las valoraciones personales, morales o políticas del objetivo de una estricta aplicación del derecho.

\section{BibLIOGRAFía}

Albanese, Susana (2008) "La internacionalización del derecho constitucional y la constitucionalización del derecho internacional". En Albanese, Susana (coordinadora): El control de convencionalidad. Buenos Aires: Editorial Ediar.

103 Maurizio, Arianna (I998) "Evoluzione Internazionale del Sistema Penale Minorile e deffetti nell'Ordinamento Italiano”, p. 9, quien identifica las reglas de Pekín (o Beijing), como una importante y fundamental individualización de reglas mínimas estándar, en materia penal de menores, haciendo sinónimos estándar y reglas. 
Alonso, Luis M. y otros (1997) La armonización fiscal en la Unión Europea. Centro de Estudios de Derecho, Economía y Ciencias Sociales. Barcelona: Editorial SL.

Beloff, Mary (1998) Los sistemas de responsabilidad penal juvenil en América Latina" en "Infancia, Ley y Democracia en América Latina. Análisis crítico del panorama legislativo en el marco de la Convención Internacional sobre los Derechos del Niño. Bogotá: Editorial Temis/ Depalma.

Benavides, María Angélica (2009) "El consenso y el margen de apreciación de los derechos humanos". Ius et Praxis, Vol. 15, $\mathrm{N}^{\circ} 1$, pp. 295-310.

Bоввiо, Norberto (2002) Teoría general del Derecho. Colombia: Editorial Temis.

Calvinho, Gustavo (2015) "El Sintagma del debido proceso". Revista Derecho Ecuador. Disponible en: http://www.derechoecuador.com/ articulos/detalle/archive/doctrinas/procedimientopenal/2015/03/09/ el-sintagma--debido-proceso

Carnevali, Raúl (2009) Problemas de Política Criminal y otros estudios. Santiago de Chile: Editorial LegalPublishing.

Chinssoni, Pierluigi (2011) "Las cláusulas generales, entre teoría analítica y dogmática jurídica”. Revista de Derecho Privado, $\mathrm{N}^{\circ} 21$, pp. 89-106.

Contreras, Pablo (2014) "Deferencia internacional y discreción nacional bajo el pacto internacional de derechos civiles y políticos". Revista de Derecho Universidad Católica del Norte, Vol. 21, No 1, pp. 21-60.

Escobar Martínez, L.M.; Benítez-Rojas, V. F.; Cárdenas Poveda, M. (2011) "La influencia de los Estándares Interamericanos de reparación en la jurisprudencia del Consejo de Estado Colombiano". Estudios Constitucionales, Año 9, No 2, pp. 165-190. Disponible en: http:// www.scielo.cl/scielo.php?pid=S0718-52002011000200005\&script=sci_ arttext

Fuentes, Ximena (2007) "El derecho internacional y el derecho interno: definitivamente una pareja dispareja”. Revista de Economía y Derecho, Vol. 15, No 4, pp. 2-35.

García Ramírez, Sergio (2012) El debido proceso, criterios de la jurisprudencia interamericana. México: Editorial Porrúa.

Hart, H. L. A. (1994) The Concept of Law, 2nd ed. Oxford: Oxford University Press.

Kelsen, Hans (1952) Principles of International Law. USA: The Law Book Exchange, Ltd).

Kelsen, Hans (1992) ¿Qué es justicia? Barcelona: Planeta-Agostini. 
Kelsen, Hans (1992) Teoría pura del derecho: introducción a la ciencia del derecho. Buenos Aires: Editorial Universitaria.

Laporta, Francisco (1987) "Sobre el concepto de derechos humanos". Doxa, $\mathrm{N}^{\circ}$ 04, pp. 23-46. Disponible en: http://dialnet.unirioja.es/ servlet/articulo? codigo $=128428$

Marcone, Julieta (2005) Hobbes: entre el iusnaturalismo y el iuspositivismo. México: Andamios, Vol. 1, No 2, pp. 123-148. Disponible en: http://www.scielo.org.mx/scielo.php?script=sci_arttex t\&pid=S1870-00632005000300006

Martínez Estay, José (2014) "Auto-restricción, deferencia y margen de apreciación. Breve análisis de sus orígenes y de su desarrollo". Estudios Constitucionales, Año 12, № 1, pp. 365-396.

Maurizio, Arianna (1998) Evoluzione Internazionale del Sistema Penale Minorile e deffetti nell'Ordinamento Italiano. Centro de Estudios de Justicia de las Américas CEJA. Disponible en: http://www. cejamericas.org/index.php/biblioteca/biblioteca-virtual/doc_ view/2397-evoluzione-internazionale-del-sistema-penal.html

Nogueira Alcalá, Humberto (2006) "Los desafíos de la sentencia de la Corte Interamericana en el caso Almonacid Arellano". Ius et Praxis, Vol. 12, $\mathrm{N}^{\circ}$ 2, pp. 363-384. Disponible en: http://www.scielo.cl/ scielo.php?script=sci_arttext\&pid=S0718-00122006000200013

Núñez Donald, Constanza (2015) "Bloque de constitucionalidad y Control de Convencionalidad en Chile: avances jurisprudenciales". Anuario de Derechos Humanos de la Universidad de Chile, $\mathrm{N}^{\circ} 11$, pp. 157-169. Disponible en: http://www.anuariocdh.uchile.cl/index. $\mathrm{php} / \mathrm{ADH} /$ article/viewFile/37497/39173

Núñez Poblete, Manuel (2011) "Sobre la doctrina del margen de apreciación nacional. La experiencia latinoamericana confrontada y el Thelos Constitucional de una técnica de adjudicación del Derecho Internacional de los Derechos Humanos". Ensayo introductorio. Grupo de Trabajo sobre Derechos Humanos Sociedad Latinoamericana de Derecho Internacional.

PÁsara, Luis (2010) "Reformas del sistema de justicia en América Latina, cuenta y balance". Sociología del Derecho. Culturas y Sistemas Jurídicos Comparados, Vol. I, UNAM.

Peredo Rojas, Marcela (2013) "El margen de apreciación del legislador y el control del error manifiesto. Algunas consideraciones a partir de la jurisprudencia del Consejo Constitucional Francés y del Tribunal Constitucional Alemán”. Estudios Constitucionales, Vol. 11, № 2.

Pérez Luño, Antonio (1987) "Concepto y Concepción de los Derechos Humanos". Doxa, No 4, pp. 47-66. 
Pérez Luño, Antonio (1997) "Los Principios Generales del Derecho, ¿un mito jurídico?". Revista de Estudios Políticos Nueva Época, N 98, pp. 9-24.

Quinche, Manuel (2009) Los estándares de la Corte Interamericana y la Ley de Justicia y Paz. Bogotá: Editorial Universidad del Rosario.

Rickert, H. (1960) Teoría de la definición. Colaboración del Instituto de Investigaciones Filosóficas, $1^{\text {a }}$ Ed. México: Universidad Nacional Autónoma de México.

Rodríguez, Sonia (2008) Los Principios Generales del Derecho. España: Editorial Universitaria Sur.

Salinas Gómez, Juan Pablo (2013) Control de convencionalidad en el Sistema Interamericano de Derechos Humanos: Alcance y recepción a partir del deber de adoptar disposiciones de Derecho Interno. Colombia: Universidad Nacional. Disponible en: http://www.bdigital.unal.edu. co/39922/

Scarpelli, Uberto (1962) Filosofia analitica, norme e valori. Milano: Editorial Comunità, pp. 56-57.

SousA, Mariana (2007) "Breve panorama de la reforma judicial en América Latina: objetivos, desafíos y resultados". El Estado de las Reformas del Estado En América Latina, publicación conjunta del Banco Mundial y Editorial Mayol, Washington, USA, pp. 99-137.

Velluzzi, Vito (2010) Le clausole generali. Semantica e politica del diritto. Milano: Quaderni di Filosofia Analitica. 